\title{
A Cognitive Analysis of Si Mohand's Translated Poetry L'Amitié Bafouée
}

\author{
Kahina MECHAT \\ Department of English \\ Mouloud Mammeri University of Tizi-Ouzou \\ Tizi-Ouzou, Algeria \\ Correspondent Author: kahina.mechat@ummto.dz \\ Souryana YASSINE \\ Department of English \\ Mouloud Mammeri University of Tizi-Ouzou \\ Tizi-Ouzou, Algeria
}

Received: 1/4/2021

Accepted: 2/11/2021

Published: 2/24/2021

\begin{abstract}
Kabyle oral poetry is the spirit of Kabyle literature. Si Mohand's poetry was and still is the subject of many studies. The current research is Cognitive and analytical and aims to explain the English translated version of poem 16 taken from L'Amitié Bafouée, using schema theory, following Semino's (2014) proposed approach to poetry analysis. Terminologies advanced by Schank and Abelson (1977), Schank's Dynamic Memory (1982), and Cook's Schema Refreshment (1994), will be used in the analysis. The study's significance is firstly shown through its corpus, i.e. previous works dealing with Si Mohand's poetry mostly made use of either the French or Kabyle versions. And secondly, through the use of a combination of terminologies advanced by the previously mentioned scholars. The study aims to answer the following main question: what is the main scene projected by the poem? And the following sub-question: what is the impact of culturally translated metaphors on readers? Results show that nine scripts need to be activated to form the betrayal Scene. Moreover, the use of literal translation in cultural metaphors specifically, led to difficulties in activating appropriate scripts in order to allow understanding to take place. In fact, understanding is determined by the reader's background knowledge. The current analysis can also be used in translation assessment, detecting cultural misunderstandings, comparative studies of poetry, and can even be introduced to teaching.

Keywords: scene, schema refreshment, schema theory, Si Mohand's translated poetry "l'Amitié Bafouée", thematic organization point (TOP)

Cite as: MECHAT, K, \& YASSINE, S. (2021). A Cognitive Analysis of Si Mohand's Translated Poetry L'Amitié Bafouée. Arab World English Journal for Translation \& Literary Studies 5 (1) 363-377. DOI: http://dx.doi.org/10.24093/awejtls/vol5no1.24
\end{abstract}




\section{Introduction}

The current study is analytical, aiming to explain the English version of a Kabyle poem of Si Mohand, who was born around 1840-1850 and died in 1902. He is considered as a philosopher and a poet whose poems are generally seen as a replica of his own life yet reflecting the spirit of his country (Feraoun, 2012). His poems' topics are, most of the time, related to love, destiny, and exile. Kabyle poetry needs to target a wider audience which is not fulfilled through the use of the Kabyle or French versions. With that said, using the English translated version will logically increase its visibility and reach a larger audience. Si Mohand's poetry was translated multiple times by different translators. But the current study relies on the French version translated by the Kabyle writer Feraoun (1960), which was later on translated by Pierre Joris into English i.e. the version used in the current analysis. The main aim of the study is to answer these questions: what is the main scene projected by poem 16? and what is the impact of cultural translated metaphors on the readers? The first hypothesis states that the main scene is related the title of the collection "L'amitié Bafouée" i.e. broken friendship. The second hypothesis asserts that the impact of the translated metaphors is the same as the one of the cultural metaphors of the French version.

\section{Literature Review}

\section{Schema Theory: Its Background and Application in Poetry Analysis}

Schema theory is a cognitive theory that sheds light on the way prior knowledge and previous experiences stored in memory interact with the input to comprehend a current situation. Semino (2014) asserted that, it was first referred to by Immanuel Kant, as structures that organize knowledge in the brain. However, its modern use is attributed to Bartlet (1932), who ascribes it to Head (1920).

The complementarity of Schank and Abelson (1977), Schank Dynamic Memory (1982) and Cook's Schema Refreshment (1994), when it comes to their views about schema theory, was the reason behind the use of a mixture of their terminologies in the current study. All scholars agreed that the activation of appropriate schemata related to the proper prior knowledge (if available) at the right time is crucial to the understanding process and determines the degree of comprehension. Schank and Abelson (1977) introduced script along with plans, goals and understanding to make sense of events using the background knowledge stored in memory. Schank and Abelson (1977) defined script as follows: "A script is a structure that describes appropriate sequences of events in a particular context... Scripts handle stylized everyday situations ... [A] script is a predetermined, stereotyped sequence of actions that defines a well-known situation" ( $p$ 41)

Semino (2014) asserted that Schank and Abelson (1977) differentiated between three types of scripts, personal ones like being nervous, situational ones like taking a taxi and physical ones like driving a car. A plan is used to make sense of an input (unknown script) i.e., plans are used to understand a situation and reach a given goal; these plans can be a script (a script used within another script), or become one after sufficient information is gathered (Semino, 2014).

Schank and Abelson's (1977) case study in the development of knowledge structures was performed on a child named Hana. They started with the idea that "an important part of the language acquisition process is the acquisition of scripts" by being dragged into an experience 
"enough times". They give the example of the acquisition and development of Hana's restaurant script at different ages. After that, they noticed her storytelling development at different ages. They deduced that "her understanding seems proportional to her limited world knowledge" when dealing with scripts or plan inferences. Their "main assertion is that first Hana knew standard scripts and then she knew how to do some rudimentary planning."

Schank's model of dynamic memory (1982) took into consideration the flexibility of memory and its ability to develop, adapt and adjust to new experiences. He advanced the following terms: scripts, scenes, memory organization pockets (MOPs), and Meta MOPs. His term "Thematic Organization points (TOPs)" is essential in the current analysis. It highlights the ability to pick up information across different domains to understand a given situation (Semino, 2014). According to the definition given above, a script is one possible realization of a scene. According to Schank (1982), a scene is underlined by the achievement of a goal, within a setting and having actions happening towards the achievement of that goal. Semino (2014) explained that Schank (1982) differentiated between three types of scenes; physical scenes dealing with settings, societal scenes taking place in a given setting between people having a relationship to accomplish a given purpose, and personal scenes are determined by personal goals.

Important notions advanced by Cook, including Schema preserving, reinforcing and adding alongside schema disrupting, are used in the current analysis. Semino (2014) mentioned that Cook distinguished between schematic knowledge based on the effect it has on the discourse. Schema reinforcing or adding, indicates that an already existing schema has been proved and confirmed by adding additional information to background knowledge forming that schema. Schema preserving means that the schema is kept as it is while schema disrupting would lead to schema change by destroying an old schema and building up a new one (Hidalgo-Dawning, 2000).

Foale and Pagett (2009) claimed that "schema theory suggests that we tend to store much of what we know in schemata, which are simply 'containers' for our experiences". They gave the example of having a "poetry schema" that contains everything in relation to poetry, then, further argued that it wasn't sufficient to understand all poems, as readers need to make connections between what they know and what they "are struggling to understand". This could be done by relating previous experiences to the real world.

Semino (2014) proposed an approach to analyse poetic text worlds based on schema theory by systematically relating it to the linguistic analysis of texts. She analyzed two poems, namely: 'A Pillowed Head' by Seamus Heaney and 'Morning Song' by Sylvia Plath". She asserted that both "are similar in two main respects: they both deal with the birth of a child and they both project worlds that, in possible-world terms, are fully compatible with the world we live in" (Semino, 2014). She further added that worlds that are considered as being realistic could represent different views of reality and "therefore be perceived differently by readers". According to her, this difference could be explained using schema theory. Semino (2014) pointed to the fact that the use of schema theory accounts for her interpretations which means that other readers with different backgrounds may interpret the poems differently. In this sense, Freeman (2020) claimed that "neuroscientists have discovered that certain synaptic pathways in the brain develop their use 
depending on exposure to environmental experience, so that every human brain is slightly different". Semino (2014) made use of terminologies advanced in: Rumelhart's Schema theory and Cognition (1980), Schank and Abelson's View on Schema Theory (1977), Schank's Dynamic Memory (1982), and Cook's Schema Refreshment (1994).

Schema theory was not used in analyzing English translated versions of Si Mohand's poems, by Joris (2012). As far as authors know, the original Kabyle versions and French translated versions were the subject of various research in different fields. The majority of the studies conducted were initially done to gather the poems and transcribe them to preserve them and get to know the Kabyle culture. This is the case of Boulifa (1904), Feraoun (1960), and Mammeri (1969), who transcribed Si Mohand's Poetry and translated it into French. Other studies on Si Mohand's Poetry in literature in general and comparative literature, in particular, were undertaken by scholars such as Connolly (2020) who shed light on the original version of the first poem of Si Mohand "Bismilleh" found in Mammeri (1969) and introduced its English version translated by Walid Bouchakour and himself. His analysis was based on the impact of the poet's life experiences, Qur'anic education mostly, on his poetry and career.

\section{The Poet}

Si Mohand's date of birth is unknown since his name does not figure in Kabylia civil status records. However, his date of death is: 1906 (Feraoun, 2012). Boulifa noted that he died in his forties i.e. when he was 46 years old. With that said, Feraoun (2012) mentioned that other testimonies confirm that when he died, he had more than sixty years old. After the rebellion of 1871, Si Mohand's father was executed and their fortune was seized by the state. This broke the family apart and Si Mohand became a vagabond. He died in 1906 at Sœurs Blanches Hospital and was buried at Sidi Said Taleb sanctum.

\section{The Translators}

Mouloud Feraoun, who transcribed and translated Si Mohand's poetry, was born on March $8^{\text {th }}, 1913$, in a village called Tizi-Hibel (Fort-National). He went to l'Ecole Normale de Bouzareah in 1932. In 1935, he became a teacher at Tizi Hibel. In 1957, he moved to Algiers and became the director of Ecole Nador. He was killed by l'OAS in March 1962.

Pierre Joris, who translated Si Mohand's poetry from French into English, is a poet, a translator, and a professor at the University of Albany. In 1990, he got a Ph.D. in Comparative Literature from Suny-Binghamton. In 1975, he got an M.A in Theory and Practice of Translation.

\section{Materials and Methods}

The study is qualitative and analytical, aiming to explain the English translated version of Poem -16- taken from L'Amitié Bafouée, in Si Mohand's poetry translated by Pierre Joris (2012), using schema theory, based on Elena Semino (2014) proposed approach.

\section{The Corpus}

Si Mohand's poetry is oral and was first transcribed by Si Said Boulifa (1904). Yet, Si Mohand's name does not appear in the title of his book: Recueil de Poésies Kabyles (Feraoun, 
2012). However, he was the one who attributed the poems to Si Mohand by mentioning his name and the oral specificity of his poetry. Feraoun (1960) was the first to mention the poet's name in the title of his book. He, furthermore, takes into consideration the historical context of the poems, gives the poet's biography and presents his work.

Finnegan (2017) classifies oral poetry within "oral literature" and claims that "oral poetry essentially circulates by oral rather than written means; in contrast to written poetry, its distribution, composition or performance are by word of mouth and not through reliance on the written or printed word" (p.16). Lahlou (2013) claims that till the XX century, Kabyle literature was mainly oral and expressed through poetry. He adds that a poem is called "Assefru" which comes from the verb "ssefru" which means "enlighten or clarify" (p.108). This means that Kabyle oral poetry tends to maintain, to clarify, and interpret reality. Social life in Kabylia is seen through oral poetry and topics such as friendship, betrayal, ingratitude, civic responsibilities, Knowledge, etc. One of the well-known poets of that period is Si Mohand Ou Mhand, as mentioned by Assaf (2019): " the works of the most famous Kabyle poet of that time, Si Mohand Ou Mhand, whose family was crushed in 1871 repression, are a constant opposition between 'then' and 'now' ( zik/ tura)" (p. 78). This confirms the fact that Kabyle oral poetry clarifies, shows, and represents Kabyle life just like Si Mohand's poetry.

\section{Analysis Procedure}

The analysis procedure is simple. Scripts embodied within the main schema, or scene, will be examined in the English version of the poem, translated by Pierre Joris. To do so, terms previously mentioned within Schank and Abelson (1977), Schank's Dynamic Memory (1982), and Cook's Schema Refreshment (1994), will be used accordingly. The figurative language and metaphors will be analyzed using TOP, a term advanced by Schank (1982). Finally, Cook's schema refreshment is introduced to put forth the poem's impact on the audience.

The activation of the Formal Schema enables the reader to know, just by taking a look at poem -16- within collection III L'Amitié Bafouée, that it is poetry and is translated into poetry as well. The original poem is oral and transcribed by Feraoun into Kabyle language. The transcribed version and the French and English translated ones are all divided into three stanzas with three verses each, organized as A-A-B/A-A-B in the original poem and rendered into free verse stanzas in both translated versions.

The analysis starts with a description of the Discourse Situation of the Poem. Then the use of definite reference is explained and linked to the activations of scripts. After that, scripts are advanced gradually to determine the main schema or scene. In fact, the analysis is going to be done stanza by stanza and then, each verse within each stanza is analyzed alone and in relation to other verses to determine, using Schank and Abelson's script (name and type), Goal, plan and understanding, the scripts incorporated within the scene projected by the translated version of $\mathrm{Si}$ Mohand's Poem, translated by Pierre Joris. 


\section{Analysis and Results \\ The Discourse Situation of the Poem}

The poet Si Mohand captured a period in Kabylia's history in this poem, seen as a form of resistance against the French colonial acts as he complains and shares the Kabyles' suffering and shame (Feraoun, 2012). The poet mentioned the traitors who have chosen to live a life of humiliation and abjectness. While he declared himself in civil disobedience and made the decision to never have an identity card or be registered anywhere in the civil status register, never take the train, the bus or use any colonial means of transportation or even have a picture, he would rather travel by foot in his homeland (Oulebsir, 2017). The focus is on the poet himself and how he unmasked the traitors. The poet makes its appearance right at the beginning of the poem through the use of the personal pronoun "I". The use of "we", in the first verse of the second stanza, "we will break but without bending", refers to all those who are still standing and fighting, including him, against these traitors, their chiefs and the colonial forces. In the second verse of the third stanza, "I prefer to leave my country", the poet joined the act of exile to himself as a preference rather than living among traitors and colonial forces that destroyed everything in his beloved region.

\section{Definite Reference and Schema Activation}

The use of definite reference means that a schema is already activated. Its use in the poem indicates that the projected communicative situation is personal and shared by the poet and the target audience. The definite article "the" was used first in the second verse of the first stanza of the poem indicating that a schema is already activated i.e., the fact that the itinerary was established by saying "from Tizi-Ouzou all the way to Akfadou", which explains the use of definite reference. The definite article "the" is also used in the third verse of the second stanza in "the chiefs", which is explained by the expectation of shared background knowledge between the poet and his audience living in the same context. The third stanza is initiated with "Exile", but then the definite article appears in "the forehead" at the end of the verse. The use of "my" in the second verse of the third stanza is, again, due to the expectation of a shared background knowledge of lecturers and the poet, which would easily understand that it refers to their own country, which is clearly stated as "my country".

\section{The Main Schema/ Scene}

The poem was taken from a collection named L'Amitié Bafouée, which indicates betrayal. This poem initially deals with the betrayal towards the land and its people by individuals who decided to work with the French colonial forces. Other subschemata are initiated in relation to this main schema.

\section{Analyzing the Stanzas}

Stanza 1

I have sworn that from Tizou-Ouzou

All the way to Akfadou

No one will impose his law on me.

The first and second verses infer the activation of two scripts. The first puts forth the act of swearing and is complemented by the third verse where the reason behind the act of swearing is 
shown. While the second delimits the borders of Kabylia region where the act of swearing is applied. Through the use of Schank and Abelson's typology of schemata encompassing scripts, plans, goal that lead to understanding (the type of the script is also mentioned), the first, second and third instantiated scripts are advanced in tables one, two, and three.

Table 1: Swearing script

\begin{tabular}{llll}
\hline Script & Type & Plans & Goal \\
\hline Swearing & Personal & -Believing in a given & -Showing pride \\
& religion & towards himself and \\
& -having a reason & anger towards \\
& behind the act of traitors. \\
& swearing & \\
\hline
\end{tabular}

Table 2. Indicating the borders of Kabylia

\begin{tabular}{|c|c|c|c|}
\hline Script & Type & Plans & Goal \\
\hline $\begin{array}{l}\text { Borderline } \\
\text { Kabylia } \\
\text { (from the east and } \\
\text { west) }\end{array}$ & Situational & $\begin{array}{l}\text {-Knowing the region } \\
\text { and the itinerary. }\end{array}$ & $\begin{array}{l}\text { Show the borders of } \\
\text { the area where the act } \\
\text { of swearing is } \\
\text { applied upon }\end{array}$ \\
\hline
\end{tabular}

These two scripts contain two" fleeting scripts", a term advanced by Schank and Ablson (1977) to refer to non-instantiated scripts (Semino, 2014). They are not necessarily activated as they take part in a bigger script activated and already understandable by itself. Those two fleeting scripts are the Tizi-Ouzou script and Akfadou Script, which are both situational. There is no need to activate those scripts since they are there only to show the borders of Kabylia. This is the case only when background knowledge is shared by the readers as they already know both places. Other readers can consider them as fleeting scripts, since understanding happens without them being activated. They also can choose to search about them and add additional knowledge to their already existing knowledge, an act called by Cook in his schema refreshment theory, schema reinforcing.

The poet declares himself in civil disobedience in the Kabylia region as no one can impose any kind of law on him. The Civil Disobedience Script, mentioned below, gathers all the previously mentioned scripts, and are in this case considered as its Plans.

Table 3. Civil disobedience script

\begin{tabular}{llll}
\hline Script & Type & Plans & Goal \\
\hline Civil disobedience & Personal & $\begin{array}{l}\text { Swearing that no one } \\
\text { in Kabylia region humiliation. } \\
\text { would impose his law } \\
\text { on the poet }\end{array}$ & \\
& & & \\
& & &
\end{tabular}

Stanza 2

We will break but without bending:

It's better to be cursed

When chiefs are pimps.

Arab World English Journal for Translation \& Literary Studies

ISSN: 2550-1542 | www.awej-tls.org 
The first verse outlines a cultural metaphor that infers self-esteem and relates it to strength and resistance. The second and third verses introduce the poet's choice to being cursed since chiefs are pimps. Both verses are introduced to explain and expand the meaning of the first verse. The scripts and the metaphors within this stanza are further defined.

Table 4. Self-esteem script

\begin{tabular}{lllll}
\hline Script & Type & Plans & Goal & \\
\hline Self-esteem & Situational & and & - love of the land \\
personal & -having courage and & -resistance & and \\
& strength & & \\
\hline
\end{tabular}

The term "Thematic Organization Points", advanced by Schank is used to make a link across domains to understand the metaphor used in "we will break, but without bending" (p241). The activation of TOP relating breaking, like an object, to the internal suffering of the poet and people sharing his beliefs is accompanied by the instantiation of a script through the use of the negative form of the gerund "bending" to indicate courage, pride and love of the land.

The fifth script introduces the choice of the poet to be cursed.

Table 5. Being cursed by choice

\begin{tabular}{lllll}
\hline Script & & Type & Plans & Goal \\
\hline $\begin{array}{l}\text { Being } \\
\text { choice }\end{array}$ & cursed & by & Personal & $\begin{array}{l}\text { Taking the decision Searching for peace } \\
\text { and having the of mind } \\
\text { courage to assume it }\end{array}$ \\
\hline
\end{tabular}

The sixth script completes the fifth script, and explains why the poet had chosen to be condemned or cursed.

Table 6. Pimping chiefs

\begin{tabular}{llll}
\hline Script & Type & Plans & Goal \\
\hline Pimping Chiefs & Situational & -betrayal and treason & Showing anger \\
& & - having no pity for towards traitors and \\
& colonized people, French colonialism \\
& especially women
\end{tabular}

A metaphor is introduced in "When the Chiefs are Pimps", by linking between the chiefs, i.e. traitors and colonial rulers, and pimps. To comprehend this metaphor, a TOP must be used to create, a link across these two elements. Usually, this later is used to indicate that those chiefs are like pimps i.e. men controlling and using prostitutes to get money as traitors and colonial rulers were known for having no pity or remorse when it comes to using women to get profit, which is the common point between the chiefs and pimps.

Stanza 3

Exile is inscribed on the forehead:

I prefer to leave my country

Than to be humiliated among these pigs.

Arab World English Journal for Translation \& Literary Studies 
This stanza contains three scripts that introduce strong emotions felt by the poet as a reaction to the treason of people of his own region, and the massive colonial destruction of the majority of Kabylia's villages, including his own.

The first script introduced in this stanza is Exile Script:

Table 7. Exile script

\begin{tabular}{llll}
\hline Script & Type & Plans & Goal \\
\hline Exile & Situational & $\begin{array}{l}\text { Being in a position } \\
\text { that entails leaving } \\
\text { the country. }\end{array}$ & \\
\hline
\end{tabular}

The first word of the first verse in the third stanza, "Exile", instantiates the activation of exile script. The reader forms a general idea about the act of being obliged to leave his country. Table 8. Inevitable exile script

\begin{tabular}{llll}
\hline Script & Type & Plans & Goal \\
\hline Inevitable exile & Personal & $\begin{array}{l}\text { Deciding to leave the } \\
\text { country }\end{array}$ & Searching for peace \\
\hline
\end{tabular}

This script complements the former and gives the reader additional insights concerning the act of exile. The poet is forced to leave the country, but this decision was taken by the poet himself as it is further mentioned that exile is inevitable through the use of the metaphor "inscribed on the forehead".

This later is an ancient well-known cultural metaphor among Kabyle people. In their culture, such expression is used to infer destiny. Anything inscribed on an individual's forehead can't be changed and is meant to happen no matter what. Those two scripts i.e., the destiny script, the inscription on the forehead script, have a common point that can be deduced by using TOP, and is the fact that either cannot be avoided or changed.

Table 9. Leaving the country by choice script

\begin{tabular}{llll}
\hline Script & Type & Plans & Goal \\
\hline $\begin{array}{l}\text { Leaving the country } \\
\text { by choice }\end{array}$ & Personal & $\begin{array}{l}\text {-Not being able to Showing preference } \\
\text { adjust to the new way and choice. } \\
\text { of life imposed by } \\
\text { colonial rulers. }\end{array}$ \\
\hline
\end{tabular}

This script adds new information in relation to the three previous scripts in this stanza. Factually, the idea of preferring to leave the country by choice reinforces the inevitable exile script as it enhances the fact that exile is an inevitable decision made by the poet himself as it is his destiny, because he can't live a life of humiliation among pimping chiefs.

Table 10. My country script

\begin{tabular}{llll}
\hline Script & Type & Plans & Goal \\
\hline My Country & Personal & Having a country & $\begin{array}{l}\text { Express and show } \\
\text { belonging }\end{array}$ \\
\hline
\end{tabular}

Arab World English Journal for Translation \& Literary Studies 
It is specified through the use of the possessive article "my" that the country in question is the poet's country. In this case, it necessary to be aware that the country of the poet is Algeria and that the poem in question is initially transcribed in Kabyle language, and that the poem which is being analyzed is its English translated version. This information is already given at the beginning of this article and is considered as stored background knowledge for the reader. The activation of the appropriate schema by the reader would lead to comprehending and deducing that the country is Algeria.

Semantically, My Country Script brings to the surface another script, which is Borders of Kabylia script, extracted from the first and second verses belonging to the first stanza, as it extends the geographical area that the poet spoke about at the beginning of his poem to include all Algeria after mentioning Kabylia region at the beginning of the poem. The poet, then, pictures the reason why he cannot live in his country in the following script presented in table 11.

Table 11. Life with no dignity script

\begin{tabular}{llll}
\hline Script & Type & Plans & Goal \\
\hline Life with no dignity & $\begin{array}{l}\text { Personal } \\
\text { situational }\end{array}$ & and $\begin{array}{l}\text { - Self-esteem } \\
\text {-Having dirty } \\
\text { pimping chiefs. }\end{array}$ & and
\end{tabular}$\quad$\begin{tabular}{l}
$\begin{array}{l}\text { Draw a clear picture } \\
\text { of the life the poet } \\
\text { does not want to live. }\end{array}$ \\
\hline
\end{tabular}

This script shows why the poet can't live in his own country. It is a personal decision yet taken while being obliged because the poet can't accept being humiliated in his own land. Within this script, two other scripts are activated when "humiliated among these pigs" is advanced. This expression contains a metaphor and includes two domains that are typically not related to one another but share one thing when used metaphorically. A TOP brings the two scripts into one i.e., pigs script and chiefs script. This later is activated because of the use of "these", meaning that the script is previously activated. Which is the case as it was activated in the third verse of the second stanza. After being metaphorically compared to pimps, the poet, this time, compares those chiefs to pigs which are known for being unclean and nasty as they love playing in the dirt. Again, the poet points to the fact that those chiefs have no conscience since they like playing in the mud just like pigs. He also repeats and upholds his disgust towards those chiefs once again at the end of the poem.

A simile is advanced in the second and third verses of this last stanza: "I prefer to leave my country" and "than to leave among these pigs". The previous script Leaving the Country by Choice is compared to the last one, which is life with no dignity, to highlight the choice of the poet as it is a turning point in his life and the life of the people of Kabylia and all Algerians.

\section{Impact of Cultural Metaphors on Readers}

When readers have the same background knowledge, the schema is either preserving (leaving the already existing schema as it is) or reinforcing (adding new information to the already existing schema). This is the case of Kabyle readers who master the English language and are familiar with some notions in translation, this category of people has enough information to decode both metaphors "we will break but without bending" and "exile is inscribed on the forehead". When readers do not have the same background knowledge as the poet but are, to a certain degree, familiar with his culture, they can decode the metaphors and understand them basically by 
searching for equivalents in their own language and culture. This is the case of Arabic Speaking community that live in Algeria, have a good level of the English language, and again, are familiar with some basic notions of translation. These individuals can deduce the meaning of these cultural metaphors since both are directly linked to two expressions used in colloquial Arabic, and are utilized in everyday communication. The use of one language to understand another is not new in the Algerian context. Bouhadiba (2012) states that:

Competency in the mother tongue is, we believe, the starting point to learn other foreign languages at school for the simple reason that be it a child or an adult, learning a foreign language always takes as a prime reference what is already acquired in term of languages (the mother tongue for the child and/or another FL for the adult (cf. learning English with transfers from Arabic or French). (p. 22)

This is further discussed by Tomas (1992) as he argues that using appropriate exercises, for one event in two different languages, can help learners to know cultural differences and develop relevant schemata. In the first previously mentioned cultural metaphor, the schema formed is reinforcing as it adds new information to an already existing schema (adding an expression in another language to the mother tongue and/or L1 expression). This shows the complexity of the sociolinguistic situation in Algeria. The example given by Mammeri (1985) (as cited in Chachou (2013), states that a Kabyle Algerian who lives in Algiers speaks Kabyle at home, but when he goes out, he has to speak Arabic, while in his job, he has to use both Arabic and French. According to Bouhadiba (2012), "Algeria is characterized by the use of three languages in contact (Arabic, French/Berber)", and specifies that Arabic and French are used in the administration and English along with French are used in scientific research while Arabic, French and Berber are used "for informal purposes" ( Lakhder, 2012, p.15).

When readers have no clue about any of the cultures (Kabyle or Arabic), the two metaphors would sound ambiguous and awkward. The schema formed most of the time is disrupting, as confusion may happen since not all readers know about the existence of such culture in Algeria in particular and the North African region in general. This confirms Cook's Claim concerning schemata since "what is schema refreshing for one reader, or one culture, may not be schema refreshing for another reader, or another culture" (Semino, 2014, p. 154)

Joris (2012), translated Mouloud Feraoun's French translated version of Poem-16-. This later translated the original version, he transcribed himself, into French using literal translation in rendering both cultural metaphors: "Nous nous briserons sans plier" and "l'exil est inscrit au front" (p 94). This means that both translators opted for literal translation to keep the original Kabyle culture present in the French and English translated versions. It is important to mention that Feraoun is familiar with the Kabyle culture as he is from Kabylia, he went to the French colonial school, and was known for introducing Kabyle words to his writings, which means that using literal translation to keep the original language identity within the French translated version is not so surprising. Pierre Joris, on the other hand, is a Luxembourg-American poet, translator, anthropologist, and essayist. According to Almeida's (2021) interview published in The ASYMPTOTE Journal, he had contact with the Algerian culture as he was an English literature 
teacher at Mentouri University in Constantine from 1976 to 1979. This might have influenced him in choosing a literal translation in these cases, as it might be a decision made by the translator since he is familiar with the French language and can easily know that such expression is the result of a literal translation and kept it as it is in the English version using a literal translation.

Finally, mastering the English language, being familiar with the Kabyle culture, and deducing that literal translation was used in translating cultural metaphors are required to activate proper scripts to reach the appropriate TOP so that understanding takes place. The confirmation and disconfirmation of the second hypothesis is conditioned by the readers' prior Knowledge.

\section{The Main Schema or Scene Type, Plans and Goal}

According to the categorization of Schank (1982), Betrayal Scene is a personal and societal scene as it deals with personal emotions felt by the poet. Yet, it has a relation to all the Kabyles, in particular, and Algerians in general. The following table illustrates better the type, plans and goal of this scene.

Table 12. Betrayal scene

\begin{tabular}{llll}
\hline Scene & Type & Plans & Goal \\
Betrayal & Personal and Societal & -declaring himself on Draw a clear picture \\
& civil disobedience. & $\begin{array}{l}\text { of Kabylia region } \\
\text { of }\end{array}$ \\
& -self-esteem & under the French \\
& -being cursed by colonization. \\
& choice. \\
& - pimping chiefs \\
& - exile is destiny. \\
& -leaving the country \\
& by choice, to avoid \\
& living a life with no \\
& dignity. \\
\hline
\end{tabular}

Scripts that are previously mentioned are all considered as "plans" of the Betrayal Scene. This means that the activation of all these scripts gradually leads to the formation of the Betrayal scene. The goal of this scene can be considered as the reason why this poem was written i.e., picturing life in Kabylia during French colonization. The projected world by the poem happens to be related to the poet's life which means that it is compatible to the real world at a given period of time of the poet's life. Factually, the first hypothesis was is partially confirmed since the overall broken friendship scene can be seen as a part of the betrayal scene.

\section{Discussion}

The analysis of Si Mohand's poem, which is a corpus-based analysis, took into consideration the result of Schank and Abelson (1977) case study on Hana as a starting point. Factually, the ability to extract scripts then do some planning to reach understanding is the basic idea of the analysis. Throughout the poem, the researchers extracted the scripts stanza by stanza and determined the types of the scripts and their goals and all that is presented in tables. Schank and Abelson (1977) asserted that the lack of Hana's world knowledge was the reason behind not 
understanding the whole script adequately, which is the second important point in the analysis and the reason behind introducing Semino's proposed approach to poetry analysis.

Semino's (2014) approach incorporated schema theory into a linguistic analysis of texts to analyze poetic text worlds. She chose two poems fully compatible with the real world and argued that they could be seen differently from readers having different backgrounds. Similarly, the current analysis highlighted these differences through the application of Schank's TOP to understand cultural metaphors. Additionally, the poem under study, though it projects a realistic world, can be challenging to people having different backgrounds i.e. not familiar with Kabyle culture, not knowing some notions in relation to translation and not mastering the English language. Contrary to Semino's analysis, the poem used in the current analysis is an English version, first translated from Kabyle into French then from French into English. The translation process made the application of a schema theory approach more complicated since it dealt with the interference of three languages along with the poet's and the translators' backgrounds, which is noticed through the use of cultural metaphors as explained in the analysis section.

In her discussion of "Pillowed Head" and "Morning Song", Semino (2014) made use of Rumelhart's Schema theory and Cognition (1980), Schank and Abelson's View on Schema Theory (1977), Schank's Dynamic Memory (1982) and Cook's Schema Refreshment (1994). In "Pillowed Head", She focused on deixis and other patterns and deviations then she discussed in detail the schemata involved in her interpretation of the poem. Furthermore, her analysis of "Morning Song" started by determining the discourse situation of the poem and figurative language used in it and then advanced the main schema and other schemata. In both poems and throughout her analysis, Semino (2014) used terms such as scene, script, MOP and TOP to describe particular types of schema. In the analysis of Si Mohand's translated poem, researchers made use Schank and Abelson's (1977) all along the analysis in addition to terminologies required in the analysis, which are: scene or main schema along with its types and TOP. In Semino's (2014) analysis, the term TOP was advanced by Schank (1982) and used in the explanation of metaphors. The main goal of Semino's analysis was to compare the worlds projected by the two poems to explain that even if both of them were fully compatible with the real world, people may still have different views about reality which would mean that they may construct different views about the same poem. The authors' goal in the analysis of Si Mohand's poem was to gradually determine the main scene of the poem, i.e. projected world which happens to be compatible to the real world of the poet's life at a given period of time. The use of TOP to explain the translated cultural metaphors highlighted the fact that the readers' background knowledge highly influenced their interpretations.

The findings of this research put forth the historical context and the poet's life as it advanced a way to understand the overall scene of the poem. Moreover, it underlined the way in which cultural metaphors were used in the French and English translated versions. Furthermore, it highlighted Kabyle culture just like Boulifa (1904), Feraoun (1960) and Mammeri (1969). If we compare it to Connolly (2020), the present study considered the poet's religion as a part in understanding the overall scene and was only mentioned in the first script of the first stanza. 


\section{Conclusion}

In this study, the researchers analyzed the English version of Si Mohand's poem using schema theory while previous works only dealt with the original Kabyle version or the French translated one. Moreover, schema theory, as far as authors know, has never been used to analyse Si Mohand's English translated poetry. The first hypothesis was partially confirmed, as the betrayal scene is related to the title of the collection "l'Amitié Bafouée", i.e. broken Friendship. While the confirmation and disconfirmation of the second hypothesis is conditioned by the readers' prior Knowledge. It is essential to mention that the study partially indicated the sociolinguistic complexity in Algeria. However, it is not a sociolinguistic study; it is a cognitive one. The occasional reference to translation is inevitable since we used the English translated version of the poem. Finally, this qualitative, cognitive and analytical study explained the English version of Si Mohand's poem using schema theory to increase the visibility of a legendary Kabyle poet and his culture.

\section{About the Authors: \\ Kahina MECHAT is a Ph.D. student in the Department of English at Mouloud Mammeri University of Tizi Ouzou, Algeria. Her research interests include, Cognitive Linguistics, Neurolinguistics, Contrastive Linguistics, Translation Studies and Poetry Analysis. https://orcid.org/0000-0003-1115-3427}

Dr. Souryana YASSINE is a professor in Language Sciences and Applied Linguistics in the Department of English at Mouloud Mammeri University of Tizi Ouzou, Algeria. She is an elected member of the scientific committee of the Faculty of Letters and Languages. He has the position of Head of the Doctoral Program of Master's course entitled Didactics of Foreign Languages. Her research interests include, Language Education, Sociolinguistics, Gender Studies, intercultural Communication, Discourse Analysis, Social Semiotics and Multimodality. https://orcid.org/0000-0001-6014-2543

\section{References}

Almeida, A. (2021) An Interview with Pierre Joris. Asymotote Journal. Retrieved December $15^{\text {th }}, 2020$ from: http://www.asymototejournal.com/interview/an-interview-pierre-joris/

Asseraf, A. (2019) Electric News in Colonial Algeria. Oxford: University Press

Bartlett, F, C. (1932). Remembering, A Study in Experimental and Social Psychology. Cambridge University Press.

Bouhadiba, F. (2012). Language Awareness amidst a Multilingual Setting: the case of Algeria. In A.

lakhder(ed.), Langues et Média en Méditerranée (pp. 15-23). Paris : L’Harmattan

Boulifa, S, A. (1904). Recueil de Poésies Kabyles. Alger : A. Jourdan

Chachou, I. (2013). La Situation Sociolinguistique de l'Algérie : pratiques plurilingues et variétés à L'œuvre. Paris: L'Harmattan

Connolly, C, T. (2020). Yale French studies: North African Poetry in French "Editor's Preface: Prelude to North African Poetry in French”. Number 137/138. Yale University Press

Cook, G. (1994). Discourse and Literature: The Interplay of Form and Mind. Oxford: Oxford University Press

Arab World English Journal for Translation \& Literary Studies 
Feraoun, M. (2012). Les Poèmes de Si Mohand [Poems of Si Mohand]. Beni-Messous, Algiers: Hibr Editions.

Feraoun, M. (1960). Les Poèmes de Si Mohand [Poems of Si Mohand]. Les Editions De Minuit

Finnegan, R. (2018). Oral Poetry: Its Nature, Significance and Social Context. $4^{\text {th }}$ Ed. Eugene: Wipf and Stock Publishers

Foale, J., \& Pagett, L. (2009). Creative Approaches to Poetry for the Primary Framework for Literacy. London and New York: Routledge

Freeman, M, H. (2020). The Poem as Icon: A Study in Aesthetic Cognition. UK: Oxford University Press

Hidalgo-Downing, L. (2000). Negation, Text Worlds, and Discourse: The Pragmatics of Fiction. (Vol. LXVI). Standford: Ablex Publishing Corporation.

Joris, P., \& Tengour, H. (2012. Poems for the Millennium (Vol. 4). Berkeley: University of California press

Mammeri, M. (1969). Les Isefra, Poèmes de Si Mohand ( Poems of Si Mohand). Paris : Maspéro

Oulebshir, R. (2017). Le Dernier Voyage de Si Mohand-Ou-Mhand (The Last Trip of Si-MohandMhand). Bejaia: Afriwen Editions

Schank, R., \& Abelson, R. (1977). Scripts, Plans, Goals and Understanding. Hillsdale, New Jersey: Lawrence Erlbaum Associates.

Semino, E. (2014). Language and World Creation in Poems and Other Texts "Schema Theory and the analysis of text worlds in poetry". UK: Lancaster University

Thomas, S, F. (1992). The Implication of Translation Theories for Language Teaching Pedagogy. University OF London: The Institute of Education

www.albany.edu. (nd). Pierre Joris C.V. Available at : https://www.albany.edu/ joris/resume.html

www.algeriades.com (2020). Mouloud Feraoun. Retrieved from: https://www.algeriades.com/mouloud-feraoun-

\section{Appendix}

\section{Appendix A: Poem-16-}

I have sworn that from Tizi-Ouzou

All the way to Akfadou

No one will impose his law on me.

We will break, but without bending:

It's better to be cursed

When the chiefs are pimps.

Exile is inscribed on the forehead:

I prefer to leave my country

Than to be humiliated among these pigs. (Joris \& Tengour, 2012, p. 241) 